\title{
Which Metrics Are Being Used to Evaluate Children and Adolescents After ACL Reconstruction? A Systematic Review
}

\author{
Peter D. Fabricant, M.D., M.P.H.," Christopher M. Brusalis, M.D., \\ Jonathan M. Schachne, B.A., the PLUTO Study Group, and Matthew J. Matava, M.D.
}

\begin{abstract}
Purpose: To identify a comprehensive list of outcome measures previously used in the literature to evaluate clinical outcomes after reconstruction of the anterior cruciate ligament (ACL) in patients 18 years of age or younger. Methods: A literature search was performed by querying MEDLINE, Embase and Cochrane computerized databases for relevant articles that reported clinical outcomes in pediatric patients undergoing ACL reconstruction. Studies that were nonclinical, that reported on patients older than 19 years, that were not available in English, or that included fewer than 10 patients were excluded. Outcome measures of all eligible studies were recorded. Results: We identified 77 studies published between 1986 and 2018 in 20 peerreviewed journals. The mean age of the patients was 13.9 years. The ACL rerupture rate was reported in $60 \%$ of studies; 32 studies $(42 \%)$ reported a rate of return to preinjury activity or sports. The use of adult-validated patient-reported outcome measures were reported in $63(82 \%)$ articles. The Lysholm (64\%), International Knee Documentation Committee (IKDC) $(56 \%)$ and Tegner $(37 \%)$ scores were the most commonly reported. Two patient-reported outcome measures designed for pediatric patients (the Pedi-IKDC and Hospital for Special Surgery Pediatric Functional Activity Brief Scale (Pedi-FABS) were employed in $5(6 \%)$ recent studies. Conclusions: There is variability across studies in the metrics used to assess clinical outcomes following ACL reconstruction in children and adolescents. Validated pediatric-specific instruments were used infrequently. Clinical Relevance: A large body of existing pediatric ACL-reconstruction literature relies on a variable set of outcome measures that have not been developed or validated for children and adolescents. More recently, contemporary studies have begun to employ pediatric- and adolescent-specific validated measures, yet their use remains uncommon.
\end{abstract}

$\mathbf{O}$ ver the past 3 decades, injury to the anterior cruciate ligament (ACL) among children and adolescents has become increasingly recognized as a significant contributor to morbidity in pediatric sports medicine. ${ }^{1,2}$ An increasingly diverse population of

From the Division of Pediatric Orthopaedic Surgery, Hospital for Special Surgery, New York, New York, U.S.A. (P.D.F., J.M.S.); Department of Orthopaedic Surgery, Hospital for Special Surgery, New York, New York, U.S.A. (P.D.F., C.M.B.); and Department of Orthopaedic Surgery, Washington University School of Medicine, St. Louis, Missouri, U.S.A. (M.J.M.).

*Peter D. Fabricant and Christopher M. Brusalis are co-first authors.

The authors report the following potential conflicts of interest or sources of funding: M.J.M. reports travel, lodging, food, faculty or speaker, and education support from Arthrex; consulting fees from Heron Therapeutics; and education support from Elite Orthopedics. Full ICMJE author disclosure forms are available for this article online, as supplementary material.

Pediatric ACL: Understanding Treatment Outcomes (PLUTO) Study Group authors (alphabetical): Christian N. Anderson, M.D. (Tennessee Orthopaedic Alliance, Nashville, Tennessee, U.S.A.), Michael T. Busch, M.D. (Children's Healthcare of Atlanta, Children's Orthopaedics of Atlanta, Atlanta, Georgia, U.S.A.), Henry G. Chambers, M.D. (Pediatric Orthopedics $\theta$ Scoliosis Center, Rady Children's Hospital, San Diego, California, U.S.A.), Melissa A. Christino, M.D. (Boston Children's Hospital, Division of Sports Medicine, Department of young athletes has resulted in growing participation in an array of organized youth sporting activities. ${ }^{3}$ A concomitant rise in ACL injuries has challenged sportsmedicine providers to develop treatment strategies tailored to young athletes. Earlier entry into organized

Orthopaedics, Harvard Medical School, Boston, Massachusetts, U.S.A.), Frank A. Cordasco, M.D., M.S. (Department of Orthopaedic Surgery, Hospital for Special Surgery, New York, New York, U.S.A.), Eric W. Edmonds, M.D. (Pediatric Orthopedics $\theta$ Scoliosis Center, Rady Children's Hospital, San Diego, California, U.S.A.), Theodore J. Ganley, M.D. (Children's Hospital Philadelphia, University of Pennsylvania School of Medicine, Philadelphia, Pennsylvania, U.S.A.), Daniel W. Green, M.D., M.S. (Department of Orthopaedic Surgery, Hospital for Special Surgery, New York, New York, U.S.A.), Benton E. Heyworth, M.D. (Boston Children's Hospital, Division of Sports Medicine, Department of Orthopaedics, Harvard Medical School, Boston, Massachusetts, U.S.A.), Mininder S. Kocher, M.D., M.P.H. (Boston Children's Hospital, Division of Sports Medicine, Department of Orthopaedics, Harvard Medical School, Boston, Massachusetts, U.S.A.), J. Todd R. Lawrence, M.D., Ph.D. (Children's Hospital Philadelphia, University of Pennsylvania School of Medicine, Philadelphia, Pennsylvania, U.S.A.), Lyle J. Micheli, M.D. (Boston Children's Hospital, Division of Sports Medicine, Department of Orthopaedics, Harvard Medical School, Boston, Massachusetts, U.S.A.), Matthew D. Milewski, M.D. (Boston Children's Hospital, Division of Sports Medicine, Department of Orthopaedics, Harvard Medical School, Boston, 
play, documented patterns of single-sport specialization and year-round competition have magnified the frequency and severity of such injuries. ${ }^{4-8}$

In concert with advancements in the surgical management of ACL injuries in youth, researchers have devised new tools for measuring the success of surgical interventions. Across health care, widespread implementation of patient-reported outcome measures (PROMs) has revolutionized the manner in which providers understand how patients respond to therapies. $^{9-11}$ Several recent studies have focused on the utility of such outcome measures in pediatric sports medicine. $^{12-14}$ To date, the plethora of reported outcome measures raises concern that data heterogeneity across the literature may impede meaningful data pooling that allows researchers to draw conclusions and to guide clinical practice. ${ }^{13}$ Moreover, outcome measures must be validated in the patient populations of interest in order to ensure the accuracy and validity of information being collected, a challenge when studying children and adolescents. ${ }^{15-17}$

The purpose of this study was to identify a comprehensive list of outcome measures previously used in the literature to evaluate clinical outcomes after ACL reconstruction in patients aged 18 years or younger. We hypothesized that the patient-reported outcomes used would vary greatly among studies and would not be validated for pediatric patients in some cases.

\section{Methods}

This systematic review was conducted in accordance with Preferred Reporting Items for Systematic Reviews and Meta-analyses (PRISMA) guidelines. ${ }^{18,19}$ Two authors performed independent queries of the scientific literature using 3 computerized literature databases (MEDLINE, Embase and Cochrane) indexed from the earliest possible date through January 17, 2018. The electronic search algorithm included the following Medical Subject Heading terms: "Adolescent" OR "child" OR "pediatrics" AND "anterior cruciate ligament" OR "anterior cruciate ligament reconstruction" AND "treatment outcome" OR "outcome assessment.". In conjunction with university librarians, a

\footnotetext{
Massachusetts, U.S.A.), Jeffrey J. Nepple, M.D. (Department of Orthopaedic Surgery, Washington University School of Medicine, St. Louis, Missouri, U.S.A.), Shital N. Parikh, M.D. (Division of Orthopaedic Surgery, Cincinnati Children's Hospital Medical Center, Cincinnati, Ohio, U.S.A.), Andrew T. Pennock, M.D. (Pediatric Orthopedics $\theta$ Scoliosis Center, Rady Children's Hospital, San Diego, California, U.S.A.), Paul Saluan, M.D. (Cleveland Clinic Orthopaedic and Rheumatologic Institute, Garfield Heights, Ohio, U.S.A.), Kevin G. Shea, M.D. (Department of Orthopedic Surgery, Stanford University, Stanford, California, U.S.A.), Eric J. Wall, M.D. (Division of Orthopaedic Surgery, Cincinnati Children's Hospital Medical Center, Cincinnati, Ohio, U.S.A.), and Samuel C. Willimon, M.D. (Children's Healthcare of Atlanta, Children's Orthopaedics of Atlanta, Atlanta, Georgia, U.S.A.).
}

comprehensive list of relevant iterations to each Medical Subject Heading term (e.g., "pediatric" OR "paediatric") was incorporated into the final search strategy (Appendix 1). Articles were included if they reported outcome measures in young patients undergoing ACL reconstruction. Outcomes measures were defined as either patient-reported outcome instrument scores or significant events in the clinical course that influence outcome following ACL surgery, such as a complication, return to preinjury activities or sports, ACL rerupture, or secondary surgery. All levels of evidence were included. Studies that were nonclinical or comprised fewer than 10 patients, conference abstracts, studies unavailable in English, and those that reported on patients older than 19 years of age were excluded. This chronologic age was selected as a cut-off because it is associated with physeal closure at the knee at a population level and is the definition currently used by the World Health Organization. ${ }^{20-23}$

Two researchers (C.M.B. and J.M.S.) independently screened the titles and abstracts of all articles using Covidence software (Covidence, Melbourne, Victoria, Australia) to determine study eligibility by applying the aforementioned criteria. ${ }^{24}$ Studies were excluded if either the title or the abstract clearly refuted eligibility $(\mathrm{N}=1,860)$. The remaining articles underwent full-text review. Discrepancies between reviewers were resolved by reaching consensus with 2 senior authors (M.J.M. and P.D.F.). Bibliographies from all included articles were reviewed manually to identify additional pertinent studies. To ensure that duplicate patient populations were not included, articles with cross-matching authors were reassessed to examine them for overlapping dates of enrollment. If 1 or more authors conducted studies with overlapping patient populations, the study with the greater number of patients, longer follow-up and/or more comprehensive outcome reporting was included. ${ }^{25}$

The methodological quality of included studies was formally assessed using the Quality Assessment Tool for Observational Cohort and Cross-Sectional Studies. ${ }^{26}$ Adapting a system utilized by Montalvo et al., ${ }^{27}$ studies were scored based on the number of

\footnotetext{
Received November 13, 2019; accepted April 15, 2020.

Address correspondence to Peter D. Fabricant, M.D., M.P.H., Pediatric Orthopaedic Surgery Service, Hospital for Special Surgery, 535 East 70th Street, New York, New York 10021,U.S.A. E-mail: fabricantp@hss.edu

(C) 2020 THE AUTHORS. Published by Elsevier Inc. on behalf of the Arthroscopy Association of North America. This is an open access article under the CC BY-NC-ND license (http://creativecommons.org/licenses/by-nc-nd/4.0/). 2666-061X/191360

https://doi.org/10.1016/j.asmr.2020.04.006
} 
Fig 1. Preferred Reporting Items for Systematic Reviews and Meta-Analyses (PRISMA) flow diagram for pediatric anterior cruciate ligament clinical outcomes literature.
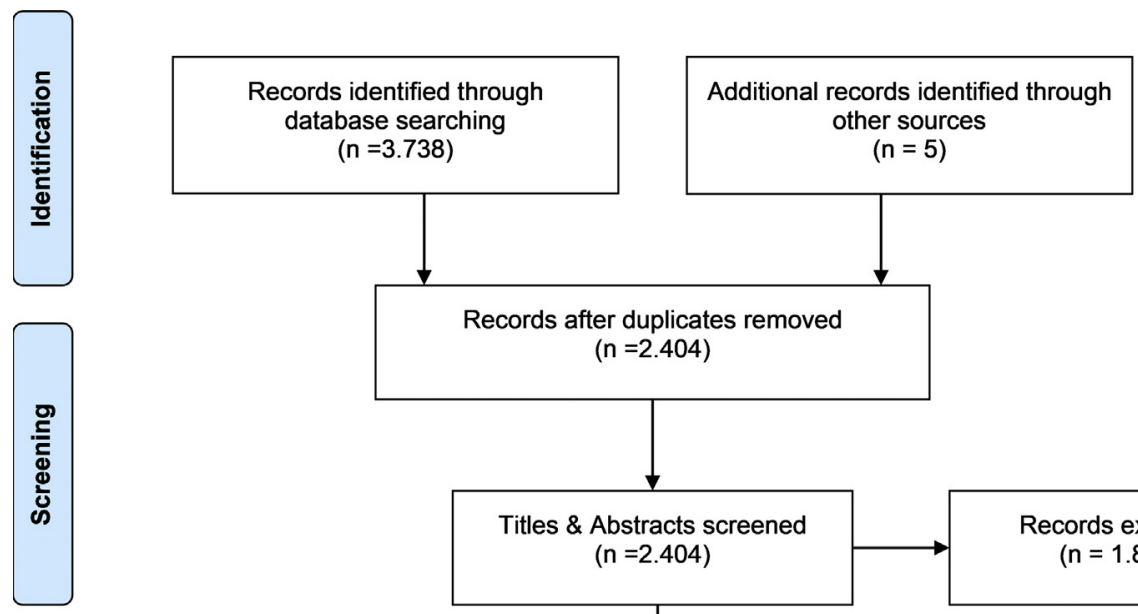

$(n=5)$

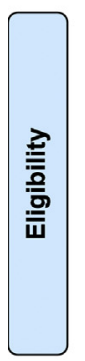

Records after duplicates removed $(n=2.404)$

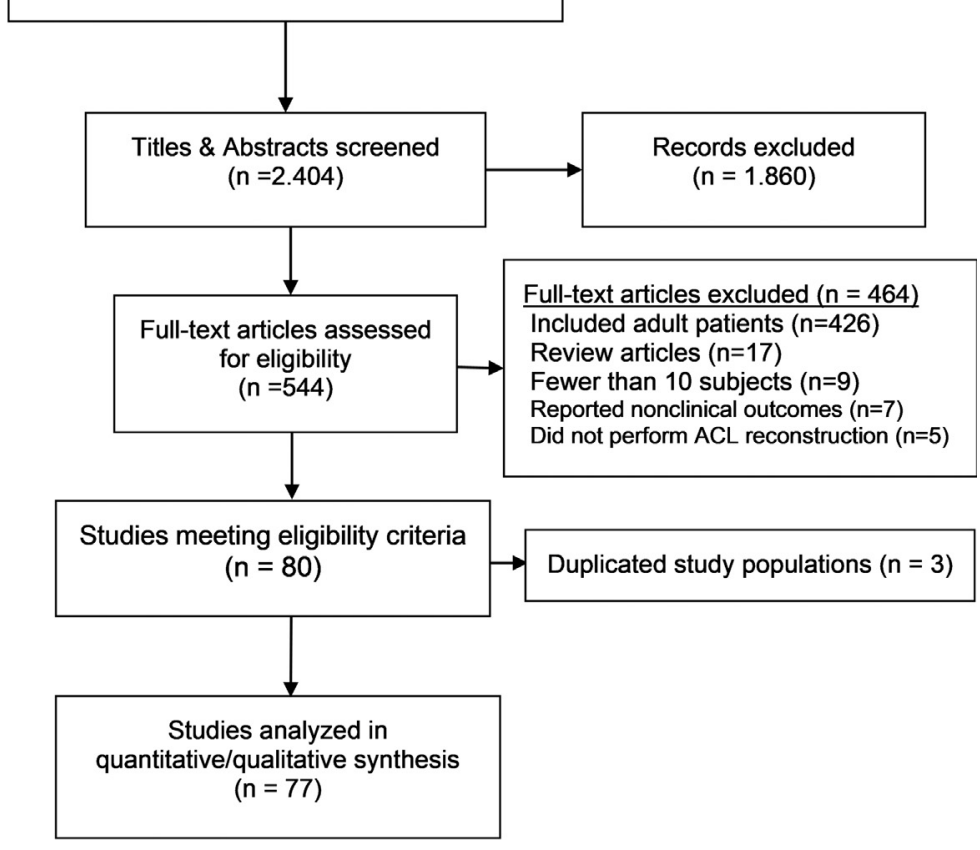

affirmative responses to the instrument's checklist of 12 relevant questions. The percentage of studies that scored $\geq 75 \%$ and $\geq 50 \%$ for relevant questions was quantified.

The study characteristics and parameters of each article were extracted and recorded using a custom spreadsheet in Microsoft Excel (Microsoft, Redmond, WA, USA). Data consisted of information regarding study design and participants' demographic information. All documented clinical outcomes identified by full-text review of included studies were recorded. Descriptive summary statistics were employed to report the frequency of the various outcome measures in the group of all studies, including the frequency and the years in which outcome measures validated for pediatric populations were used.

\section{Results}

From 2,404 unique articles initially identified, 80 articles met the eligibility criteria. Three studies were subsequently removed to avoid including duplicate patient populations, ${ }^{28-30}$ leaving 77 studies in the final qualitative review (Fig 1). Agreement between the 2 primary reviewers had a free marginal kappa of 0.67 , indicative of substantial agreement. ${ }^{31}$

\section{General Characteristics}

Seventy-seven articles reporting the clinical outcomes of pediatric and adolescent patients undergoing ACL reconstruction were analyzed. ${ }^{31-107}$ Studies were performed by primary authors from 17 different countries and published in 20 different peer-reviewed journals, dated between 1986 and 2018 (Fig 2). Of the articles, 71 $(92 \%)$ were retrospective in design, and 66 studies $(86 \%)$ were composed of level 4 evidence. Level 3 studies used comparison groups to evaluate variables such as graft type ${ }^{91,101}$ or performed a cost-effectiveness analysis. ${ }^{100}$ No level 1 or level 2 studies were identified. The mean number of patients per study was $78 \pm 141.3$ (range 10 to 902 participants), consisting of $44 \%$ female patients. The mean chronological age at the time of surgery was $13.9 \pm 1.5$ years (range 10.7 to 17.2 years). Twenty-seven studies $(35 \%)$ reported on patients' Tanner stage, and 9 studies (12\%) reported patients' skeletal 
Pediatric ACL Reconstruction: Publications by Year

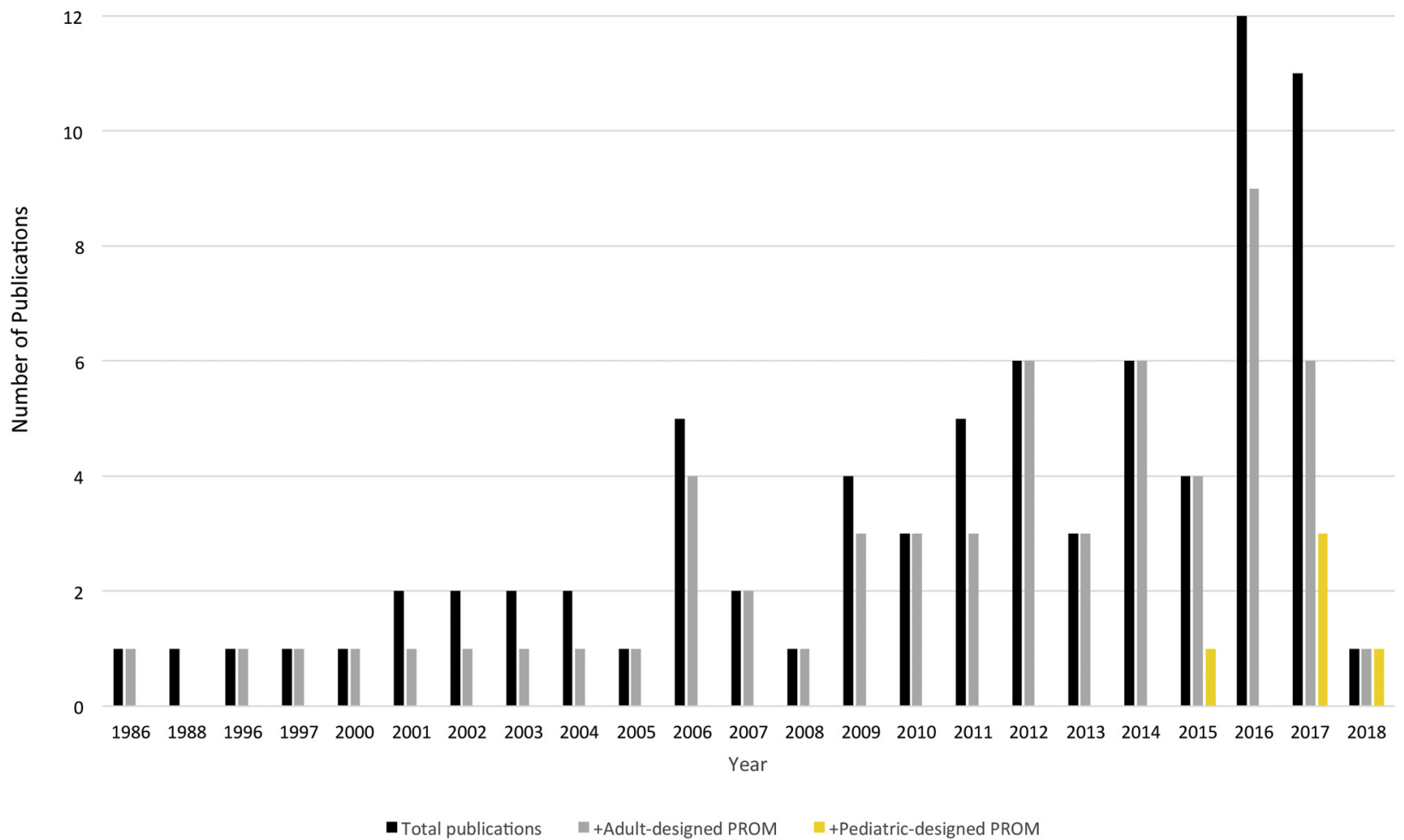

Fig 2. The number of pediatric ACL reconstruction publications has increased over the past 20 years. Pediatric-specific patientreported outcome measures (PROMs) have been implemented in a minority of studies in recent years.

age through 1 of a variety of methods. The mean duration of follow-up was $4.2 \pm 2.9$ years (range 0.4 to 18.3 years). Individual patient data were reported in 17 studies $(21 \%)$; 6 studies fulfilled at least $75 \%$ of Quality Assessment Tool criteria, and 67 studies fulfilled at least $50 \%$ of the criteria. Ten studies fulfilled fewer than $50 \%$ of criteria. All studies reported on the graft type used to perform the ACL reconstruction.

\section{Clinician-Reported Outcome Measures}

The rates at which several postoperative clinical outcomes are reported in the existing literature are summarized in Table 1. Additionally, postoperative leglength discrepancy and angular deformity were described in $60 \%$ of studies, whereas postoperative

Table 1. Reporting of Objective Outcome Measures

\begin{tabular}{ll}
\hline \multicolumn{1}{c}{ Clinical Outcome Metric } & $\begin{array}{c}\text { \% of Studies }(\mathrm{N}=77) \\
\text { Reporting Metric }\end{array}$ \\
\hline ACL rerupture rate & $60 \%$ of studies \\
Revision ACL reconstruction rate & $55 \%$ of studies \\
Rate of subsequent knee surgery & $44 \%$ of studies \\
Postoperative complication rate & $33 \%$ of studies \\
$\quad$ Infection rate & $22 \%$ of studies \\
Arthrofibrosis rate & $14 \%$ of studies \\
Nerve injury rate & $12 \%$ of studies \\
Rate of contralateral ACL rupture & $13 \%$ of studies \\
\hline
\end{tabular}

radiographic measurements were reported in $31 \%$ of studies. Nine studies $(12 \%)$ reported on overall longitudinal growth following surgery. Two studies used preoperative full-length lower-extremity alignment radiographs as a comparison for postoperative radiographic data. ${ }^{35,95}$ General assessments of range of motion were described in $39 \%$ of the articles. Instrumented ligament testing was performed in 56\% of the articles. The KT arthrometer (Medmetric, San Diego, CA, USA) was the most commonly used instrument, and specific force settings were reported in $16 \%$ of the studies (6 of 37) that used the device.

Thirty-two studies $(42 \%)$ reported rates of return to preinjury activities or sports. Of these studies, "return to sport" was defined as patients' preinjury sports level in $17(53 \%)$ studies and "competitive sport" in $6(19 \%)$ studies. Of the studies, $6(19 \%)$ did not define the return-to-sport outcome explicitly. One study reported on rate of return to "cutting or pivoting" sports. ${ }^{51}$ One study defined "return to sport" as International Knee Documentation Committee (IKDC) level 5 activity. ${ }^{90}$ Finally, l study categorized return to sports participation as "very strenuous, strenuous, or moderate." ${ }^{71}$

\section{Patient-Reported Outcome Measures}

PROMs were reported in $63(82 \%)$ articles; 14 total PROMs were used variably across studies (Fig 3A, B). 


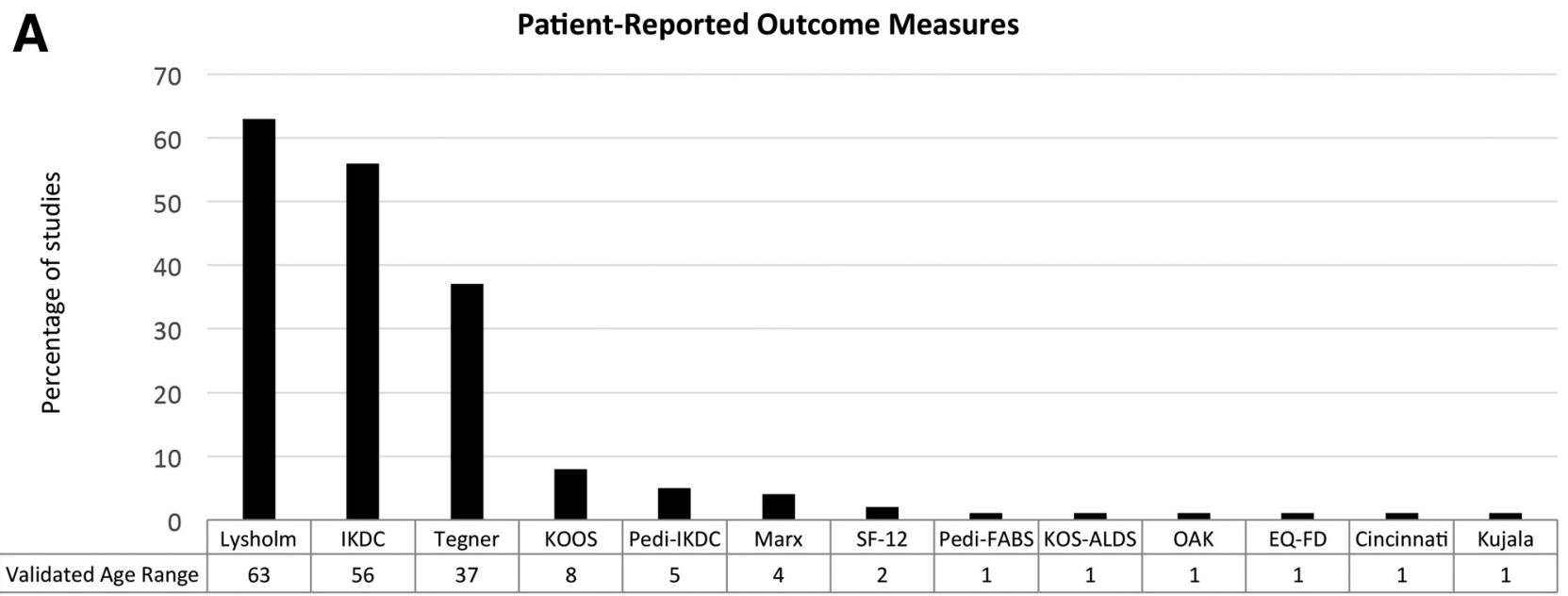

B

Number of PROMs Per Study

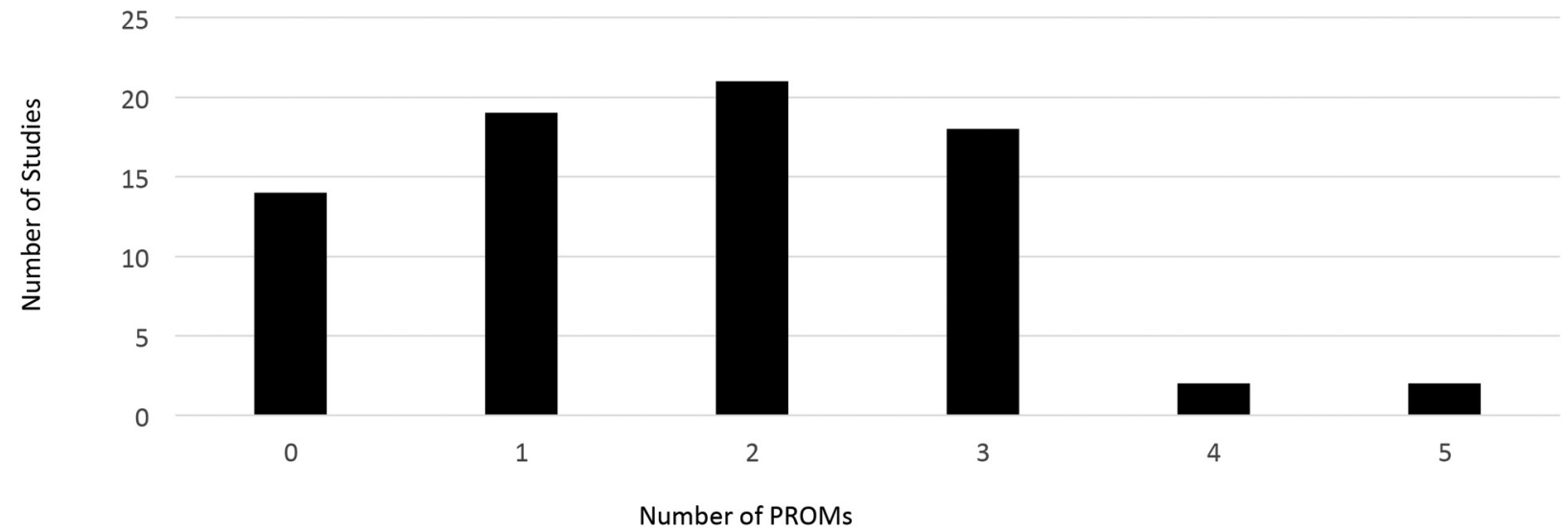

Fig 3. (A) Patient-reported outcome measures (PROMs) were used inconsistently across studies. Pediatric-designed instruments (Pediatric International Knee Documentation Committee Subjective Knee Form [Pedi-IKDC] and Pediatric Functional Activity Brief Scale [Pedi-FABS]) were employed in a small minority of studies. (B) The number of PROMs used per study was variable. One asterisk $(*)$ indicates a PROM that was originally designed and validated in adults and later validated in a pediatric population; 2 asterisks $\left.{ }^{* *}\right)$ indicate a PROM that was originally designed and validated in a pediatric population. The OAK scale has not been validated in English in an American population. Included PROMs: EQ-5D, EuroQol Group-5 Dimensions; KOS-ALDS, Knee Outcome Survey-Activities of Daily Living Scale; IKDC, International Knee Documentation Committee questionnaire; KOOS, Knee injury and Osteoarthritis Outcome Score; Marx, Hospital for Special Surgery Modified Marx Activity Rating Scale; Pedi-FABS, HSS Pediatric Functional Activity Brief Scale; Pedi-IKDC, Pediatric IKDC; SF, short form. OAK, Orthopädische Arbeitsgruppe Knie.

The number of PROMs used per study ranged from 0 to 5. The Lysholm $(64 \%),{ }^{108}$ IKDC $^{109}(56 \%)$ and Tegner Activity Scale ${ }^{110}(37 \%)$ scores were the most commonly reported. Ten studies reported all 3 PROMs, and 2 PROMs, which were specifically created and validated for use with pediatric patients, the PediIKDC $^{111}$ and the Hospital for Special Surgery Pediatric Functional Activity Brief Scale (HSS Pedi-FABS), ${ }^{112}$ were employed in $5(6 \%)$ studies. Considering that the Pedi-IKDC was first published in May 2011, only $15 \%(6 / 34)$ of studies published in May 2013 or later used a pediatric-specific PROM. Focusing on this latter subgroup provides a 2-year lag time during which new studies were performed when a pediatric-designed and validated outcome measure was available in the literature. Four PROMs were originally developed and validated in adult patients and later validated in pediatric patients (Fig 3A). Fourteen studies (18\%) reported 0 PROMs in their patient cohorts. Patients' self-assessments were reported in a minority of studies, including rates of general satisfaction in $9 \%$ of studies, pain scores in $8 \%$ of studies and Likert-scale assessments of knee function in $5 \%$ of studies.

\section{Discussion}

The findings of the present study demonstrate that use of PROMs to evaluate pediatric ACL reconstruction is neither standardized nor typically validated for the 


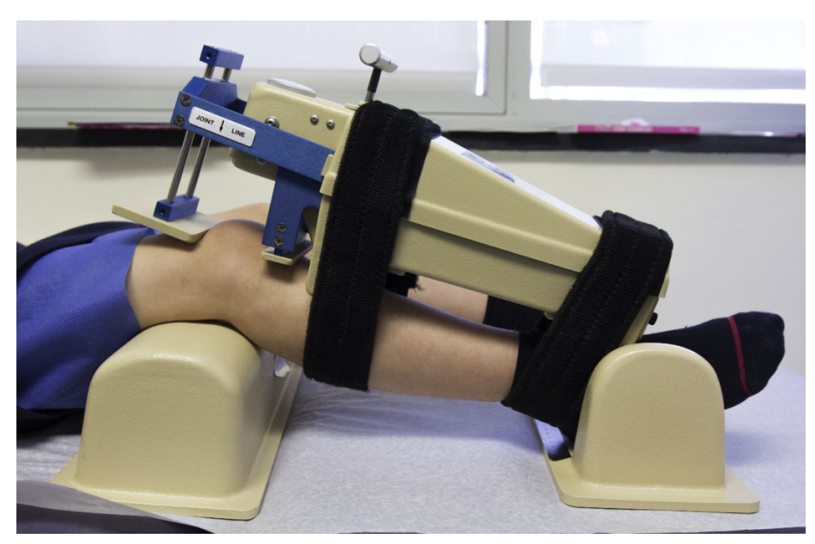

Fig 4. Photograph of a standard KT-1000 arthrometer on a young athlete's left leg. Even on the smallest setting, the device is unable to fit a pediatric patient properly, as illustrated by the joint line indicator (white label with black arrow meant to align with joint), which aligns above the superior pole of the patella.

patient population being studied. Patients' subjective perceptions and attitudes toward their medical care have become increasingly relevant in outcomes assessment across health care. Patient-centered data for ACL reconstruction have shown greater correlation with overall patient satisfaction than physiciancentered assessment or objective clinical data. ${ }^{13}$ In turn, use of patient-reported outcome measures has gained widespread popularity. However, $19 \%$ of the 77 studies reported no PROMs, which is clearly a weakness of the available literature in terms of allowing for an understanding of the true implications of surgical intervention for ACL rupture in children and adolescents. In assessing trends in the use of different metrics over time, we believe that these findings should encourage future studies to apply more consistently a standardized set of age-appropriate outcome measures and, ultimately, improve the study and treatment of ACL injuries in children and adolescents.

The lack of high-quality evidence in studies identified in the present systematic review is consistent with prior investigations into the literature concerning pediatric and adult ACL reconstruction. ${ }^{13,114}$ The vast majority of studies were conducted retrospectively, which constrains the data available for analysis and precludes use of newer PROMs, which have greater applicability to pediatric populations. It is important to consider that many studies were conducted prior to the development of survey instruments validated in pediatric populations. Gebhard et al. ${ }^{46}$ explicitly cited the lack of a pediatric-focused survey as a limitation to their work. The present analysis demonstrates that although many of the prior studies appropriately used the best methodological tools available at the time, investigators of future studies should be aware of newer means of improving the quality of data being gathered. A validated instrument must demonstrate test-retest reliability, construct validity and internal consistency when applied to a sample population representative of the group under study (i.e., children and adolescents). ${ }^{112}$ Future work is needed to determine whether further delineation of age groups among patients younger than 18 years old is warranted. Moreover, clinical research focused on pediatric patients requires customization beyond PROMs. For instance, Gebhard et al. ${ }^{46}$ illustrated how the KT-1000, the instrument used for testing ligamentous laxity in $48 \%$ of included studies, may not be appropriately sized for children and could, therefore, give erroneous results (Fig 4).

This study identified 14 unique survey instruments (Fig 3A) employed to address the clinical efficacy of ACL reconstruction in children and adolescents. Such variability in methodology impairs efforts to aggregate data or draw more powerful conclusions. Standardized tools would also allow for the use of fewer overall survey instruments, which translates to less time spent by participants in completing questionnaires. In the present analysis, 35\% of studies utilizing PROMs required participants to complete 3 or more separate survey instruments. Unfortunately, there is no universally accepted gold standard outcome measure or minimum number or PROMs that will provide a comprehensive assessment of patients' function following pediatric ACL reconstruction. However, using fewer, more ageappropriate survey instruments reduces the risk of survey fatigue, decreases participant attrition and procures better data from respondents. ${ }^{115-117}$

Return to sports participation is often a highly prioritized goal for patients following ACL reconstruction. Despite $42 \%$ of studies' quantifying the rate of return to

Table 2. Clinical Outcomes Used by the PLUTO Study Group

\begin{tabular}{ll}
\hline \multicolumn{1}{c}{ Clinical Outcome } & Measurement Instrument \\
\hline $\begin{array}{l}\text { Knee function at } 2 \text { years } \\
\text { post-ACL reconstruction }\end{array}$ & $\triangleright$ Pedi-IKDC \\
Health-related quality of life & $>$ Pediatric Quality of Life \\
& Inventory \\
Graft failure & $>$ Physical examination (Lachman \\
& test, pivot-shift test) \\
& $>$ Magnetic resonance imaging \\
& $>$ Reoperation \\
& $>$ HSS Pedi-FABS \\
Activity level & $>$ Physical Activity Questionnaire \\
& $>$ Physical examination \\
Growth disturbance & $>$ Hip-to-ankle radiograph until \\
& skeletal maturity \\
Subsequent meniscal or & $>$ Physical examination \\
chondral injury & $>$ Magnetic resonance imaging \\
& $>$ Reoperation
\end{tabular}

ACL, anterior cruciate ligament; HSS Pedi-FABS, Hospital for Special Surgery Pediatric Functional Activity Brief Scale; Pedi-IKDC, Pediatric International Knee Documentation Committee Subjective Knee Form; PLUTO, Pediatric ACL: Understanding Treatment Outcomes. 
sports, there was minimal description of how this outcome was determined. Nonetheless, several studies provided compelling ancillary data that may become useful if reported more commonly. Holwein et al. ${ }^{88}$ reported the mean time that participants spent playing sports pre- and postoperatively. Calvo et al. ${ }^{79}$ reported on athletes' subjective knee instability upon return to sports. Dekker et al. ${ }^{98}$ reported the number of sports played after surgery, as well as whether athletes returned to their primary sport. Consensus on defining return to preinjury sports participation, as well as identifying the most useful ancillary outcomes related to sports participation, will benefit future studies. To that end, the PLUTO study group ${ }^{119}$ is prospectively collecting outcome measures after pediatric and adolescent ACL reconstruction (Table 2).

\section{Limitations}

This systematic review has several limitations that must be considered. The low overall rigor of constituent studies highlights a continued need for prospective studies that employ appropriate comparative cohort and/or control groups. Furthermore, studies were excluded if they contained adult patients. This was done in order to increase the overall rigor of this systematic review so it could focus exclusively on data reporting in studies of pediatric and adolescent patients, rather than analyze any study that contained patients younger than 19 years of age. Additionally, articles not available in English translation were excluded. Such a restriction in our literature review may have excluded additional PROMs and created a selection bias that underestimates the true variability of study design in the pediatric literature concerning ACLs. Nonetheless, 17 countries were represented in the final dataset, including many in which English is not the native language. Interestingly, 1 study also suggested that restricting systematic reviews to the English language does not introduce bias into systematic reviews. ${ }^{118}$ Finally, the current study aimed to provide a comprehensive account of all clinical outcomes pertaining to pediatric ACL reconstruction by not setting date limits for study inclusion. Advancements in surgical management, methodological design and data collection likely all contribute to differences among studies from 1988 to 2018 . However, a recent study evaluating the pediatric ACL literature from 2010 to 2016 in a limited number of journals demonstrated significant heterogeneity in clinical outcomes reporting, consistent with the findings of the current review. ${ }^{13}$

\section{Conclusions}

There is significant variability across studies in the metrics used to assess clinical outcomes following ACL reconstruction in children and adolescents. Validated pediatric-specific instruments are used infrequently.

\section{References}

1. Dodwell ER, Lamont LE, Green DW, Pan TJ, Marx RG, Lyman S. 20 years of pediatric anterior cruciate ligament reconstruction in New York state. Am J Sports Med 2014;42:675-680.

2. Adirim TA, Cheng TL. Overview of injuries in the young athlete. Sport Med 2003;33:75-81.

3. Hulteen RM, Smith JJ, Morgan PJ, et al. Global participation in sport and leisure-time physical activities: A systematic review and meta-analysis. Prev Med (Baltim) 2017;95:14-25.

4. Fabricant PD, Lakomkin N, Sugimoto D, Tepolt FA, Stracciolini A, Kocher MS. Youth sports specialization and musculoskeletal injury: A systematic review of the literature. Phys Sportsmed 2016:44:257-262.

5. Brenner JS. Sports specialization and intensive training in young athletes. Pediatrics 2016;138:e20162148e20162148.

6. Jayanthi NA, LaBella CR, Fischer D, Pasulka J, Dugas LR. Sports-specialized intensive training and the risk of injury in young athletes: A clinical case-control study. Am J Sports Med 2015:43:794-801.

7. Post EG, Trigsted SM, Riekena JW, et al. The Association of Sport Specialization and training volume with injury history in youth athletes. Am J Sports Med 2017;45: 1405-1412.

8. LaPrade RF, Agel J, Baker J, et al. AOSSM Early Sport Specialization Consensus Statement. Orthop J Sport Med 2016;4:232596711664424.

9. Black N. Patient reported outcome measures could help transform healthcare. BMJ 2013;346:f167.

10. Shore BJ, Murphy RF, Hogue GD. Quality, safety, value: From theory to practice management, what should we measure? J Pediatr Orthop 2015;35:S61-S66.

11. Phillips L, Carsen S, Vasireddi A, Mulpuri K. Use of patient-reported outcome measures in pediatric orthopaedic literature. J Pediatr Orthop 2018;38:393-397.

12. Moksnes H, Engebretsen L, Risberg MA. The current evidence for treatment of ACL injuries in children is low: A systematic review. J Bone Jt Surg-Ser A 2012;94: 1112-1119.

13. Brusalis CM, Lakomkin N, Suryavanshi JR, et al. Clinical outcome reporting in youth ACL literature is widely variable. Orthop J Sport Med 2017;5: 2325967117724431.

14. Gao B, Dwivedi S, Fabricant PD, Cruz AIJ. Patterns in outcomes reporting of operatively managed pediatric patellofemoral instability: A systematic review and metaanalysis. Am J Sports Med 2019;47:1516-1524.

15. Oak SR, O'Rourke C, Strnad G, et al. Statistical comparison of the pediatric versus adult IKDC subjective knee evaluation form in adolescents. Am J Sports Med 2015;43:2216-2221.

16. Vitale MG, Levy DE, Johnson MG, et al. Assessment of quality of life in adolescent patients with orthopaedic problems: Are adult measures appropriate? J Pediatr Orthop 2001;21:622-628.

17. Viehweger E, Jouve JL, Simeoni MC. Outcome evaluation in pediatric orthopedics. Orthop Traumatol Surg Res 2014;100:S113-S123. 
18. Moher D, Liberati A, Tetzlaff J, Altman DG. Preferred reporting items for systematic reviews and metaanalyses: The PRISMA statement. PLoS Med 2009;6: el000097.

19. Panic N, Leoncini E, de Belvis G, Ricciardi W, Boccia S. Evaluation of the endorsement of the preferred reporting items for systematic reviews and meta-analysis (PRISMA) statement on the quality of published systematic review and meta-analyses. PLoS One 2013;8: e83138.

20. Calfee RP, Sutter M, Steffen JA, Goldfarb CA. Skeletal and chronological ages in American adolescents: Current findings in skeletal maturation. J Child Orthop 2010;4: 467-470.

21. O'Connor JE, Coyle J, Spence LD, Last J. Epiphyseal maturity indicators at the knee and their relationship to chronological age: Results of an Irish population study. Clin Anat 2013;26:755-767.

22. O'Connor JE, Bogue C, Spence LD, Last J. A method to establish the relationship between chronological age and stage of union from radiographic assessment of epiphyseal fusion at the knee: An Irish population study. J Anat 2008;212:198-209.

23. HIV/AIDS: Definition of key terms. World Health Organization, https://www.who.int/hiv/pub/guidelines/arv2013/ intro/keyterms/en/. Published 2013. Accessed December 26, 2018.

24. Covidence systematic review software. Veritas Health Innovation, Melbourne, Australia.

25. Harris JD, Quatman CE, Manring MM, Siston RA, Flanigan DC. How to write a systematic review. Am J Sports Med 2014;42:2761-2768.

26. National Heart, Lung, and Blood Institute. Quality assessment tool for observational cohort and cross-sectional studies. Bethesda Natl Institutes Heal Dep Heal Hum Serv, 2014, http://www.nhlbi.nih.gov/health-pro/guidelines/indeve lop/cardiovascular-risk-reduction/tools/cohort. Accessed January 17, 2018.

27. Montalvo AM, Schneider DK, Yut L, et al. "What's my risk of sustaining an ACL injury while playing sports?" A systematic review with meta-analysis. Br J Sports Med 2019;53:1003-1012.

28. Webster KE, Feller JA. Exploring the high reinjury rate in younger patients undergoing anterior cruciate ligament reconstruction. Am J Sports Med 2016;44:2827-2832.

29. Kocher MS, Garg S, Micheli LJ. Physeal sparing reconstruction of the anterior cruciate ligament in skeletally immature prepubescent children and adolescents. $J$ Bone Jt Surg-Ser A 2005;87:2371-2379.

30. Landis JR, Koch GG. The measurement of observer agreement for categorical data. Biometrics 1977;33: 159-174.

31. Lipscomb A, Anderson A. Tears of the anterior cruciate ligament in adolescents. J Bone Joint Surg Am 1986;68: 19-28.

32. McCarroll JR, Rettig AC, Shelbourne KD. Anterior cruciate ligament injuries in the young athlete with open physes. Am J Sports Med 1988;16:44-47.

33. Janarv PM, Nyström A, Werner S, Hirsch G. Anterior cruciate ligament injuries in skeletally immature patients. J Pediatr Orthop 1996;16:673-677.
34. Pressman AE, Letts RM, Jarvis JG. Anterior cruciate ligament tears in children: An analysis of operative versus nonoperative treatment. J Pediatr Orthop 1997;17: 505-511.

35. Aronowitz ER, Ganley TJ, Goode JR, Gregg JR, Meyer JS. Anterior cruciate ligament reconstruction in adolescents with open physes. Am J Sports Med 2000;28: $168-175$.

36. Edwards P, Grana W. Anterior cruciate ligament reconstruction in the immature athlete: Long-term results of intra-articular reconstruction. Am J Knee Surg 2001;14: 232-237.

37. Hofmeister EP, Gillingham BL, Bathgate MB, Mills WJ. Results of anterior cruciate ligament reconstruction in the adolescent female. J Pediatr Orthop 2001;21:302-306.

38. Aichroth PM, Patel DV, Zorrilla P. The natural history and treatment of rupture of the anterior cruciate ligament in children and adolescents. J Bone Jt Surg 2002;84: 38-41.

39. Fuchs R, Wheatley W, Uribe JW, Hechtman KS, Zvijac JE, Schurhoff MR. Intra-articular anterior cruciate ligament reconstruction using patellar tendon allograft in the skeletally immature patient. Arthroscopy 2002;18: 824-828.

40. Anderson A. Transepiphyseal replacement of the anterior cruciate ligament in skeletally immature patients: A preliminary report. J Bone Joint Surg Am 2003;85-A: $1255-1263$.

41. Guzzanti V, Falciglia F, Stanitski CL. Preoperative evaluation and anterior cruciate ligament reconstruction technique for skeletally immature patients in Tanner stages 2 and 3. Am J Sports Med 2003;31:941-948.

42. Shelbourne K, Gray T, Wiley B. Results of transphyseal anterior cruciate ligament reconstruction using patellar tendon autograft in Tanner stage 3 or 4 adolescents with clearly open growth plates. Am J Sports Med 2004;32: 1218-1222.

43. Woods GW, O'Connor DP. Delayed anterior cruciate ligament reconstruction in adolescents with open physes. Am J Sports Med 2004;32:201-210.

44. Seon J, Song E, Yoon T, Park S. Transphyseal reconstruction of the anterior cruciate ligament using hamstring autograft in skeletally immature adolescents. J Korean Med Sci 2005;20:1034-1038.

45. Gaulrapp H, Haus J. Intraarticular stabilization after anterior cruciate ligament tear in children and adolescents: Results 6 years after surgery. Knee Surg, Sport Traumatol Arthrosc 2006;14:417-424.

46. Gebhard F, Ellermann A, Hoffmann F, Jaeger JH, Friederich NF. Multicenter-study of operative treatment of intraligamentous tears of the anterior cruciate ligament in children and adolescents: Comparison of four different techniques. Knee Surg Sport Traumatol Arthrosc 2006; 14:797-803.

47. McIntosh AL, Dahm DL, Stuart MJ, Al Almet. Anterior cruciate ligament reconstruction in the skeletally immature patient. J Arthrosc Relat Surg 2006;22:1325-1330.

48. Sankar WN, Wells L, Sennett BJ, Wiesel BB, Ganley TJ, Combined anterior cruciate ligament and medial collateral ligament injuries in adolescents. J Pediatr Orthop 2006;26:733-736. 
49. Thompson M, Flynn BSJ, Wells L, Theodore J. Single incision arthroscopic ACL reconstruction in skeletally immature patients with direct visualization of the femoral and tibial physes. Orthopedics 2006;29:3-7.

50. Arbes S, Resinger C, Vécsei V, Nau T. The functional outcome of total tears of the anterior cruciate ligament (ACL) in the skeletally immature patient. Int Orthop 2007;31:471-475.

51. Kocher MS, Smith JT, Zoric BJ, Lee B, Micheli LJ. Transphyseal anterior cruciate ligament reconstruction in skeletally immature pubescent adolescents. J Bone Jt Surg-Ser A 2007;89A:2632-2639.

52. Liddle A, Imbuldeniya A, Hunt D. Low high arsenic flow rate. J Bone Joint Surg Br 2008;90-B:1317-1322.

53. Cohen M, Ferretti M, Quarteiro M, et al. Transphyseal anterior cruciate ligament reconstruction in patients with open physes. Arthroscopy 2009;25:831-838.

54. Henry J, Chotel F, Chouteau J, Fessy MH, Bérard J, Moyen B. Rupture of the anterior cruciate ligament in children: Early reconstruction with open physes or delayed reconstruction to skeletal maturity? Knee Surg Sport Traumatol Arthrosc 2009; 17:748-755.

55. Trentacosta NE, Vitale MA, Ahmad CS. The effects of timing of pediatric knee ligament surgery on short-term academic performance in school-aged athletes. Am J Sports Med 2009;37:1684-1691.

56. Wells L, Dyke JA, Albaugh J, Ganley T. Adolescent anterior cruciate ligament reconstruction: A retrospective analysis of quadriceps strength recovery and return to full activity after surgery. J Pediatr Orthop 2009;29: 486-489.

57. Kopf S, Schenkengel JP, Wieners G, Stärke C, Becker R. No bone tunnel enlargement in patients with open growth plates after transphyseal ACL reconstruction. Knee Surg Sport Traumatol Arthrosc 2010;18:1445-1451.

58. Krych AJ, Pitts RT, Dajani KA, Stuart MJ, Levy BA, Dahm DL. Surgical repair of meniscal tears with concomitant anterior cruciate ligament reconstruction in patients 18 years and younger. Am J Sports Med 2010;38: 976-982.

59. Streich N, Barié A, Gotterbarm T, Keil M, Schmitt H. Transphyseal reconstruction of the anterior cruciate ligament in prepubescent athletes. Knee Surg. Sport Traumatol Arthrosc 2010;18:1481-1486.

60. Bonnard C, Fournier J, Babusiaux D, Planchenault M, Bergerault F, de Courtivron B. Physeal-sparing reconstruction of anterior cruciate ligament tears in children: Results of 57 cases using patellar tendon. Bone Joint J $2011 ; 93-B: 542-547$.

61. Courvoisier A, Grimaldi M, Plaweski S. Good surgical outcome of transphyseal ACL reconstruction in skeletally immature patients using four-strand hamstring graft. Knee Surg Sport Traumatol Arthrosc 201 1;19:588-591.

62. Mauch C, Arnold MP, Wirries A, Mayer RR, Friederich NF, Hirschmann MT. Anterior cruciate ligament reconstruction using quadriceps tendon autograft for adolescents with open physes: A technical note. Sport Med Arthrosc Rehabil Ther Technol 2011;3:7.

63. Nikolaou P, Kalliakmanis A, Bousgas D, Zourntos S. Intraarticular stabilization following anterior cruciate ligament injury in children and adolescents. Knee Surg Sport Traumatol Arthrosc 2011;19:801-805.

64. Nwachukwu BU, McFeely ED, Nasreddine A, et al. Arthrofibrosis after anterior cruciate ligament reconstruction in children and adolescents. J Pediatr Orthop 2011;31:811-817.

65. Ellis HB, Matheny LM, Briggs KK, Pennock AT, Steadman JR. Outcomes and revision rate after bonepatellar tendon-bone allograft versus autograft anterior cruciate ligament reconstruction in patients aged 18 years or younger with closed physes. Arthrosc J Arthrosc Relat Surg 2012;28:1819-1825.

66. Hui C, Roe J, Ferguson D, Waller A, Salmon L, Pinczewski L. Outcome of anatomic transphyseal anterior cruciate ligament reconstruction in Tanner stage 1 and 2 patients with open physes. Am J Sports Med 2012;40:1093-1098.

67. Kim S-J, Shim D-W, Park K-W. Functional outcome of transphyseal reconstruction of the anterior cruciate ligament in skeletally immature patients. Knee Surg Relat Res 2012;24:173-179.

68. Memeo A, Pedretti L, Miola F, Albisetti W. Anterior cruciate ligament recostruction with bone-patellar tendon-bone autograft in Tanner 3 stage patients with open physes. J Pediatr Orthop Part B 2012;21:415-420.

69. Redler LH, Brafman RT, Trentacosta N, Ahmad CS. Anterior cruciate ligament reconstruction in skeletally immature patients with transphyseal tunnels. Arthrosc J Arthrosc Relat Surg 2012;28:1710-1717.

70. Reinhardt KR, Hammoud S, Bowers AL, Umunna BP, Cordasco FA. Revision ACL reconstruction in skeletally mature athletes younger than 18 years. Clin Orthop Relat Res 2012;470:835-842.

71. Goddard M, Bowman N, Salmon LJ, Waller A, Roe JP, Pinczewski LA. Endoscopic anterior cruciate ligament reconstruction in children using living donor hamstring tendon allografts. Am J Sports Med 2013;41:567-574.

72. Koizumi H, Kimura M, Kamimura T, Hagiwara K, Takagishi K. The outcomes after anterior cruciate ligament reconstruction in adolescents with open physes. Knee Surg Sport Traumatol Arthrosc 2013;21:950-956.

73. Kumar S, Ahearne D, Hunt DM. Transphyseal anterior cruciate ligament reconstruction in the skeletally immature: Follow-up to a minimum of sixteen years of age. J Bone Jt Surg-Ser A 2013;95:el.

74. Cassard X, Cavaignac E, Maubisson L, Bowen M. Anterior cruciate ligament reconstruction in children with a quadrupled semitendinosus graft: Preliminary results with minimum 2 years of follow-up. J Pediatr Orthop 2014;34:70-77.

75. Demange MK, Camanho GL. Nonanatomic anterior cruciate ligament reconstruction with double-stranded semitendinosus grafts in children with open physes: Minimum 15-year follow-up. Am J Sports Med 2014;42: 2926-2932.

76. Engelman G, Carry P, Hitt K, Polousky J, Vidal A. Comparison of allograft versus autograft anterior cruciate ligament reconstruction graft survival in an active adolescent cohort. Am J Sports Med 2014;42: 2311-2318. 
77. Lemaitre G, Salle de Chou E, Pineau V, et al. ACL reconstruction in children: A transphyseal technique. Orthop Traumatol Surg Res 2014;100:S261-S265.

78. Schmale GA, Kweon C, Larson RV, Bompadre V. High satisfaction yet decreased activity 4 years after transphyseal ACL reconstruction. Clin Orthop Relat Res 2014;472:2168-2174.

79. Calvo R, Figueroa D, Gili F, et al. Transphyseal anterior cruciate ligament reconstruction in patients with open physes: 10-year follow-up study. Am J Sports Med 2015;43:289-294.

80. Herman S, Lefevre N, Bohu Y. Anterior cruciate ligament tears in children. J Traumatol du Sport 2015;32:46-55.

81. Månsson $\mathrm{O}$, Sernert N, Rostgard-Christensen L, Kartus J. Long-term clinical and radiographic results after delayed anterior cruciate ligament reconstruction in adolescents. Am J Sports Med 2015;43:138-145.

82. Clifton Willimon S, Jones CR, Herzog MM, May KH, Leake MJ, Busch MT. Micheli anterior cruciate ligament reconstruction in skeletally immature youths: A retrospective case series with a mean 3-year follow-up. Am J Sports Med 2015:43:2974-2981.

83. Chicorelli AM, Micheli LJ, Kelly M, Zurakowski D, MacDougall R. Return to sport after anterior cruciate ligament reconstruction in the skeletally immature athlete. Clin J Sport Med 2016;26:266-271.

84. Giudici L, Fabbrini R, Garro L, Arima S, Gigante A, Tucciarone A. Arthroscopic transphyseal anterior cruciate ligament reconstruction in adolescent athletes. J Orthop Surg 2016;24:307-311.

85. Domzalski M, Karauda A, Grzegorzewski A, Lebiedzinski R, Zabierek S, Synder M. Anterior cruciate ligament reconstruction using the transphyseal technique in prepubescent athletes: Midterm, prospective evaluation of results. Arthrosc-J Arthrosc Relat Surg 2016;32:1141-1146.

86. Faunø P, Rømer L, Nielsen T, Lind M. The risk of transphyseal drilling in skeletally immature patients with anterior cruciate ligament injury. Orthop J Sport Med 2016;4:2325967116664685.

87. Ho B, Edmonds E, Chambers H, Bastrom T, Pennock A. Risk factors for early ACL reconstruction failure in pediatric and adolescent patients: A review of 561 cases. J Pediatr Orthop 2018;38:388-392.

88. Holwein C, Hinterwimmer S, Mayr HO, et al. Functional outcome after transphyseal anterior cruciate ligament reconstruction in young patients with open growth plates. Knee 2016;23:1121-1132.

89. Larson C, Heikes C, Ellingson C, et al. Allograft and autograft transphyseal anterior cruciate ligament reconstruction in skeletally immature patients: Outcomes and complications. Arthroscopy 2016;32:860-867.

90. Morgan MD, Salmon LJ, Waller A, Roe JP, Pinczewski LA. Fifteen-year survival of endoscopic anterior cruciate ligament reconstruction in patients aged 18 years and younger. Am J Sports Med 2016;44:384-392.

91. Nelson IR, Chen J, Love R, Davis BR, Maletis GB, Funahashi TT. A comparison of revision and rerupture rates of ACL reconstruction between autografts and allografts in the skeletally immature. Knee Surg Sport Traumatol Arthrosc 2016;24:773-779.
92. Severyns M, Lucas G, Jallageas R, et al. ACL reconstruction in 11 children using the Clocheville surgical technique: Objective and subjective evaluation. Orthop Traumatol Surg Res 2016;102:S205-S208.

93. Siebold R, Takada T, Feil S, Dietrich C, Stinton S, Branch T. Anatomical "C"-shaped double-bundle versus single-bundle anterior cruciate ligament reconstruction in pre-adolescent children with open growth plates. Knee Surg Sport Traumatol Arthrosc 2016;24:796-806.

94. Volpi P, Cervellin M, Bait C, et al. Trans-physeal anterior cruciate ligament reconstruction in adolescents. Knee Surg Sport Traumatol Arthrosc 2016;24:707-711.

95. Cordasco FA, Mayer SW, Green DW. All-inside, allepiphyseal anterior cruciate ligament reconstruction in skeletally immature athletes: Return to sport, incidence of second surgery, and 2-year clinical outcomes. Am J Sports Med 2017;45:856-863.

96. Cruz A, Fabricant P, McGraw M, Rozell J, Ganley T, Wells L. All-epiphyseal ACL reconstruction in children: Review of safety and early complications. J Pediatr Orthop 2017;37:204-209.

97. DeFrancesco C, Storey E, Flynn J, Ganley T. Pediatric ACL Reconstruction and Return to the Operating Room: Revision is Less Than Half of the Story. J Pediatr Orthop 2019;39:516-520.

98. Dekker TJ, Godin JA, Dale KM, Garrett WE, Taylor DC, Riboh JC. Return to sport after pediatric anterior cruciate ligament reconstruction and its effect on subsequent anterior cruciate ligament injury. J Bone Jt Surg Am 2017;99:897-904.

99. Graziano J, Chiaia T, Mille P De, Nawabi DH, Green DW, Cordasco FA. Return to sport for skeletally immature athletes after ACL reconstruction: Preventing a second injury using a quality of movement assessment and quantitative measures to address modifiable risk factors. Orthop J Sport Med 2017;5:e1-el0.

100. Jacobs CA, Burnham JM, Makhni E, Malempati CS, Swart E, Johnson DL. Allograft augmentation of hamstring autograft for younger patients undergoing anterior cruciate ligament reconstruction: Clinical and cost-effectiveness analyses. Am J Sports Med 2017;45: 892-899.

101. Pennock A, Ho B, Parvanta K, et al. Does allograft augmentation of small-diameter hamstring autograft ACL grafts reduce the incidence of graft retear? Am J Sports Med 2017;45:334-338.

102. Reid D, Leigh W, Wilkins S, Willis R, Twaddle B, Walsh S. A 10-year retrospective review of functional outcomes of adolescent anterior cruciate ligament reconstruction. J Pediatr Orthop 2017;37:133-137.

103. Wall EJ, Ghattas PJ, Eismann EA, Myer GD, Carr P. Outcomes and complications after all-epiphyseal anterior cruciate ligament reconstruction in skeletally immature patients. Orthop J Sport Med 2017;5: 2325967117693604.

104. Webster KE, Feller JA, Whitehead TS, Myer GD, Merory PB. Return to sport in the younger patient with anterior cruciate ligament reconstruction. Orthop J Sport Med 2017;5:el-e4.

105. Zoller S, Toy K, Wang P, Ebramzadeh E, Bowen R. Temporal relation of meniscal tear incidence, severity, 
and outcome scores in adolescents undergoing anterior cruciate ligament reconstruction. Knee Surg Sports Traumatol Arthrosc 2017;25:215-221.

106. Kocher MS, Heyworth BE, Fabricant PD, Tepolt FA, Micheli LJ. Outcomes of physeal-sparing ACL reconstruction with Iliotibial band autograft in skeletally immature prepubescent children. J Bone Jt Surg 2018;100:1087-1094.

107. Kohl S, Stutz C, Decker S, et al. Mid-term results of transphyseal anterior cruciate ligament reconstruction in children and adolescents. Knee 2014;21:80-85.

108. Lysholm J, Gillquist J. Evaluation of knee ligament surgery results with special emphasis on use of a scoring scale. Am J Sports Med 1982;10:150-154.

109. Hefti F, Muller W, Jakob RP, Staubli HU. Evaluation of knee ligament injuries with the IKDC form. Knee Surg Sports Traumatol Arthrosc 1993;1:226-234.

1 10. Tegner Y, Lysholm J. Rating systems in the evaluation of knee ligament injuries. Clin Orthop Relat Res 1985:43-49.

111. Kocher MS, Smith JT, Iversen MD, et al. Reliability, validity, and responsiveness of a modified International Knee Documentation Committee Subjective Knee Form (Pedi-IKDC) in children with knee disorders. Am J Sports Med 2011;39:933-939.

112. Fabricant PD, Robles A, Downey-Zayas T, et al. Development and validation of a pediatric sports activity rating scale: the Hospital for Special Surgery Pediatric
Functional Activity Brief Scale (HSS Pedi-FABS). Am J Sports Med 2013:41:2421-2429.

113. Kocher MS, Steadman JR, Briggs K, Zurakowski D, Sterett WI, Hawkins RJ. Determinants of patient satisfaction with outcome after anterior cruciate ligament reconstruction. J Bone Joint Surg Am 2002;84-A: 1560-1572.

114. Makhni EC, Padaki AS, Petridis PD, et al. High variability in outcome reporting patterns in high-impact ACL literature. J Bone Joint Surg Am 2015;97: 1529-1542.

115. Hochheimer CJ, Sabo RT, Krist AH, Day T, Cyrus J, Woolf SH. Methods for evaluating respondent attrition in web-based surveys. J Med Internet Res 2016;18:e301.

116. McCambridge J, Kalaitzaki E, White IR, et al. Impact of length or relevance of questionnaires on attrition in online trials: Randomized controlled trial. J Med Internet Res 2011;13:e96.

117. Hoerger M. Participant dropout as a function of survey length in internet-mediated university studies: Implications for study design and voluntary participation in psychological research. Cyberpsychol Behav Soc Netw 2010;13:697-700.

118. Morrison A, Polisena J, Husereau D, et al. The effect of English-language restriction on systematic review-based meta-analyses: A systematic review of empirical studies. Int J Technol Assess Health Care 2012;28:138-144. 


\section{Appendix I. Systematic Review Comprehensive Search Terms}

\section{PUBMED}

"adolescent"[MeSH] OR "adolescent"[TW] OR "adolescents"[TW] OR "youth"[TW] OR "child"[MeSH] OR "child"[TW] OR "children"[TW] OR "teenager"[TW] OR "teenagers" [TW]

OR "infant"[MeSH] OR "infant"[TW] OR "infants"[TW] OR "pediatrics"[MeSH] OR "pediatrics"[TW] OR "pediatric"[TW] OR "paediatric"[TW] OR "paediatrics"[TW] OR "juvenile" $[\mathrm{TW}]$ AND "Anterior Cruciate Ligament/surgery"[Mesh] OR "Anterior Cruciate Ligament Reconstruction"[Mesh] OR ("anterior"[Tw] AND "cruciate"[Tw] AND "ligament" $[\mathrm{Tw}])$ OR "anterior cruciate ligament"[Tw] OR "acl"[Tw] AND "treatment outcome"[MeSH] OR ("treatment" [Tw] AND "outcome"[Tw]) OR "treatment outcome"[Tw] OR "outcome assessment (health care)"[MeSH] OR ("outcome"[Tw] AND "assessment"[Tw] AND "(health"[Tw] AND "care)" [Tw]) OR "outcome assessment (health care)"[Tw] OR ("outcome"[Tw] AND "assessment"[Tw]) OR "outcome assessment" [Tw] OR "clinical outcomes" [Tw]

OR "outcome instruments" [Tw] OR "functional outcomes"[Tw] OR "risk factors"[MeSH] OR risk factors [Tw] OR ("patient"[Tw] AND "reported"[Tw] AND "outcome"[Tw] AND "measures"[Tw])

OR "patient reported outcome measures" [Tw]

\section{EMBASE}

('adolescent'/exp) OR (adolescent:ti,ab,de,tn) OR (adolescents:ti,ab,de,tn) OR (youth:ti,ab,de,tn) OR ('child'/exp) OR (child:ti,ab,de,tn) OR (children:ti,ab,de,tn)

OR (teenager:ti,ab,de,tn) OR (teenagers:ti,ab,de,tn) OR ('infant'/exp)

OR (infant:ti,ab,de,tn) OR (infants:ti,ab,de,tn) OR ('pediatrics'/exp)

OR (pediatrics:ti,ab,de,tn) OR (pediatric:ti,ab,de,tn) OR (paediatric:ti,ab, de,tn)

OR (paediatrics:ti,ab,de,tn) OR (juvenile:ti,ab,de,tn) AND ('Anterior Cruciate Ligament Reconstruction'/ exp) OR (anterior:ti,ab,de,tn AND cruciate:ti,ab,de,tn AND ligament:ti,ab,de,tn) OR ("anterior cruciate ligament":ti,ab,de,tn) OR (acl:ti,ab,de,tn) AND ('treatment outcome'/exp)
OR (treatment:ti,ab,de,tn AND outcome:ti,ab,de,tn) OR ("treatment outcome":ti,ab,de,tn)

OR ('outcome assessment'/exp) OR (outcome:ti,ab,de,tn AND assessment:ti,ab,de,tn AND (health:ti,ab,de,tn AND care):ti,ab,de,tn) OR ("outcome assessment (health care) ":ti,ab,de,tn)

OR (outcome:ti,ab,de,tn AND assessment:ti,ab,de,tn) OR ("outcome assessment":ti,ab,de,tn)

OR ("clinical outcomes":ti,ab,de,tn) OR ("outcome instruments":ti,ab,de,tn) OR ("functional outcomes":ti,ab,de,tn) OR ('risk factor'/exp OR "risk factors":ti,ab, de,tn)

OR (patient:ti,ab,de,tn AND reported:ti,ab,de,tn AND outcome:ti,ab,de,tn AND measures:ti,ab,de,tn) OR ("patient reported outcome measures":ti,ab,de,tn)

\section{COCHRANE}

([mh adolescent]) OR (adolescent:ti,ab,kw) OR (adolescents:ti,ab,kw) OR (youth:ti,ab,kw)

OR ([mh child]) OR (child:ti,ab,kw) OR (children:ti,ab,kw) OR (teenager:ti,ab,kw) OR (teenagers:ti,ab,kw) OR ([mh infant]) OR (infant:ti,ab,kw) OR (infants:ti,ab,kw)

OR ([mh pediatrics]) OR (pediatrics:ti,ab,kw) OR (pediatric:ti,ab,kw) OR (paediatric:ti,ab,kw)

OR (paediatrics:ti,ab,kw) OR (juvenile:ti,ab,kw) And ([mh "Anterior Cruciate Ligament/surgery"])

OR ([mh "Anterior Cruciate Ligament Reconstruction"]) OR (anterior:ti,ab,kw AND cruciate:ti,ab,kw AND ligament:ti,ab, $\mathrm{kw}$ ) OR ("anterior cruciate ligament":ti,ab,kw) OR (acl:ti,ab,kw) AND ([mh "treatment outcome"]) OR (treatment:ti,ab,kw AND outcome:ti,ab,kw)

OR ("treatment outcome":ti,ab,kw) OR ([mh "outcome assessment (health care)"])

OR ((outcome:ti,ab,kw) AND (assessment:ti,ab,kw) AND (health:ti,ab,kw) AND (care:ti,ab,kw))

OR ("outcome assessment (health care) ":ti,ab,kw) OR (outcome:ti,ab,kw AND assessment:ti,ab,kw) OR ("outcome assessment":ti,ab,kw) OR ("clinical outcomes":ti,ab,kw)

OR ("outcome instruments":ti,ab,kw) OR ("functional outcomes":ti,ab,kw) OR ([mh "risk factors"]) OR ("risk factors":ti,ab,kw) OR ((patient:ti,ab,kw) AND (reported:ti,ab,kw) AND (outcome:ti,ab,kw) AND (measures:ti,ab,kw)) OR ("patient reported outcome measures":ti,ab,kw). 